\title{
Nucleotide Bound to rab11a Controls Localization in Rod Cells But Not Interaction with Rhodopsin
}

\author{
Nicholas J. Reish, ${ }^{1,2}$ Evan R. Boitet, ${ }^{1,3}$ Katie L. Bales, ${ }^{1,3}$ and $\oplus^{\circledR}$ Alecia K. Gross ${ }^{1,2,3}$ \\ ${ }^{1}$ Evelyn F. McKnight Brain Institute, ${ }^{2}$ Department of Neurobiology, and ${ }^{3}$ Department of Vision Sciences, School of Optometry, University of Alabama at \\ Birmingham, Birmingham, Alabama 35294
}

Precise vectorial transport of rhodopsin is essential for rod photoreceptor health and function. Mutations that truncate or extend the $\mathrm{C}$ terminus of rhodopsin disrupt this transport, and lead to retinal degeneration and blindness in human patients and in mouse models. Here we show that such mutations disrupt the binding of rhodopsin to the small GTPase rab11a. The rhodopsin-rab11a interaction is a direct binding interaction that does not depend on the nucleotide binding state of rab11a. Expression of EGFP-rab11a fusion proteins in Xenopus laevis photoreceptors revealed that the nucleotide binding status of rab11a affects its subcellular localization, with GTP-locked mutants concentrated in the inner segment and GDP-locked mutants concentrated in the outer segment. shRNA-mediated knockdown of rab1la in rods led to shortened outer segments and retinal degeneration. Together, our results show the critical importance of direct rhodopsin-rab1la interactions for the formation and maintenance of vertebrate photoreceptors.

Key words: protein interactions; protein trafficking; rab11a; rhodopsin

\section{Introduction}

Rod photoreceptors sense light using a specialized organelle known as the outer segment, a unique structure consisting of a primary cilium and a stack of closely spaced membranous disks that are contained within a plasma membrane. This structure is continuously generated on a daily basis (Young, 1967). Disc generation is critically dependent on the presence of the light-sensing protein rhodopsin, as rhodopsin knock-out mice do not form outer segments and undergo retinal degeneration (Lem et al., 1999). Many genetic mutations that cause retinal degeneration occur in the rhodopsin molecule itself, reducing its stability or affecting its trafficking (Hollingsworth and Gross, 2012). The C terminus of rhodopsin containing the ciliary targeting signal VXPX has been found by several groups to be essential for proper rhodopsin trafficking and disk formation (Tam et al., 2000; Gross et al., 2006; Chuang et al., 2007; Mazelova et al., 2009).

As an integral membrane protein, rhodopsin can only move between subcellular compartments by vesicular trafficking or lateral diffusion in a membrane. Rhodopsin traffics between the

Received May 13, 2014; revised Sept. 23, 2014; accepted Sept. 26, 2014.

Author contributions: N.J.R. and A.K.G. designed research; N.J.R., E.R.B., K.L.B., and A.K.G. performed research; A.K.G. contributed unpublished reagents/analytic tools; N.J.R., E.R.B., K.L.B., and A.K.G. analyzed data; N.J.R., E.R.B., K.L.B., and A.K.G. wrote the paper.

This work was supported the National Eye Institute (Grant EY019311), the EyeSight Foundation of Alabama, the Karl Kirchgessner Foundation, and the E. Matilda Ziegler Foundation for the Blind (A.K.G.); and the UAB Medical Scientist Training Program (Grant T32GM008361, N.J.R.). We thank Xiaogang Cheng for technical assistance; Orson Moritz for the PXOP0.8 expression plasmid; Wei Guo and Ben Margolis for the gifts of plasmids encoding rab11a; Paul Hargrave and W. Clay Smith for the rhodopsin N-terminal antibodies A5-3-12 and B6-30N; Chenbei Chang for help with X. laevis husbandry; and Dusanka Deretic and the members of the Gross laboratory for helpful discussions.

The authors declare no competing financial interests.

Correspondence should be addressed to Dr. Alecia K. Gross, SHEL 906, 1825 University Boulevard, Birmingham, AL 35294.E-mail: agross@uab.edu.

DOI:10.1523/JNEUROSCI.1943-14.2014

Copyright $\odot 2014$ the authors $\quad 0270-6474 / 14 / 3414854-10 \$ 15.00 / 0$
Golgi and the distal inner segment (IS) in lipid vesicles (Deretic and Papermaster, 1991) and may traffic into the outer segment (OS) in vesicular form (Sung and Chuang, 2010) or through intraflagellar transport (Bhowmick et al., 2009), or by mechanisms not yet described. The requirement for the C-terminal targeting sequence of rhodopsin for proper trafficking implies that at least one protein binds selectively to it, and more likely a series of such proteins that shepherd it through various subcellular compartments. Indeed, it has been reported that this sequence is bound by Tctex (Yeh et al., 2006), SARA (Chuang et al., 2007), and the small GTPase Arf4 (Mazelova et al., 2009).

We and our colleagues have previously shown that mice homozygous for a knock-in of a human rhodopsin-EGFP fusion gene ( $h r h o G / h r h o G$ ) into the endogenous rhodopsin locus have a failure of outer segment formation and resultant retinal degeneration, whereas in heterozygous mice, the fusion protein traffics normally (Gross et al., 2006). Mice homozygous for the truncation mutation Q344X also undergo retinal degeneration (Sandoval et al., 2014). We hypothesized that both the extension and truncation of the $\mathrm{C}$ terminus of rhodopsin might abrogate binding of trafficking components vital for outer segment localization and/or disk formation.

Here we identify the small GTPase rab1la as a major C terminusdependent rhodopsin binding protein in the mammalian retina. Importantly, rab1la binds directly to rhodopsin independently of its GDP-GTP binding status. The nucleotide binding status of rab11a does, however, control its subcellular localization within the rod photoreceptors of transgenic Xenopus laevis tadpoles. Expression of a dominant-negative rab11a and rab11a ${ }^{\mathrm{N} 124 \mathrm{I}}$, and knockdown of rab1la via an miR-30-based hairpin in tadpole rods led to ectopic process formation, shortened outer segments, and cell death. Together, these data highlight the importance of rab11a in rhodopsin trafficking and rod cell viability. 


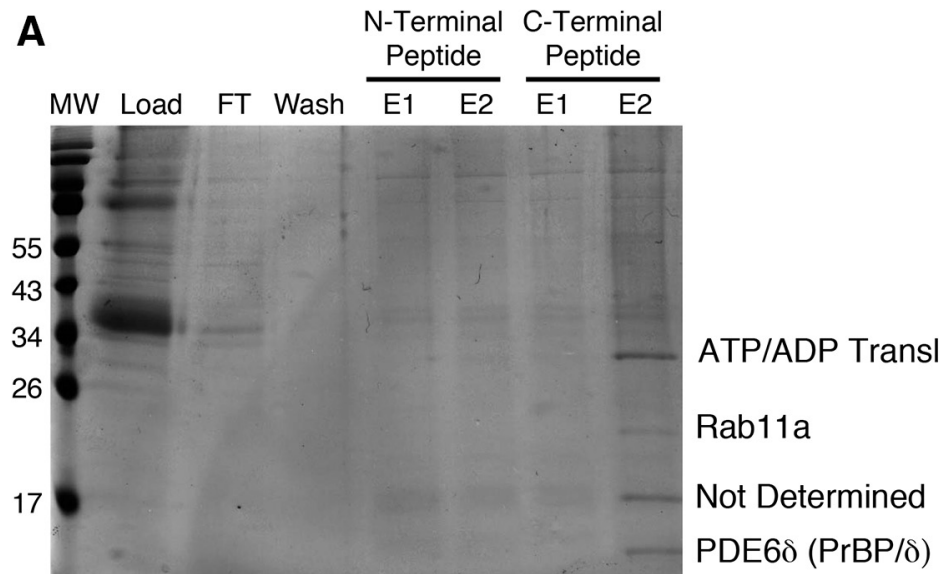

B

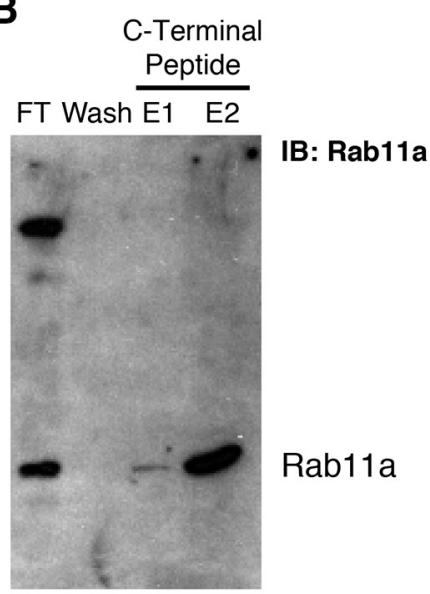

C

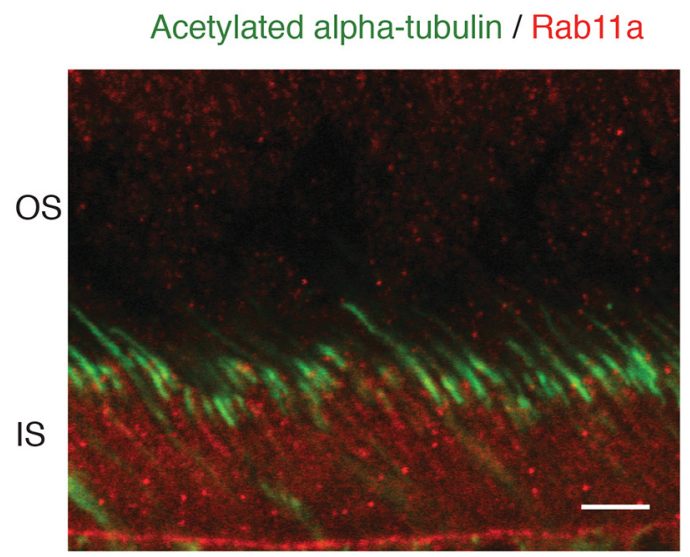

Figure 1. Rab11a binds to the C terminus of rhodopsin. $\boldsymbol{A}$, Affinity chromatography followed by SDS-PAGE identified four small proteins binding to the $C$ terminus of rhodopsin. Three of the four proteins eluted by the $C$-terminal peptide were identified by mass spectroscopy: ant2, rab11a, and PDE6 $\delta$. $\boldsymbol{B}$, Western blot confirms that rab11a is pulled down by the $\mathbf{C}$ terminus of rhodopsin. $\boldsymbol{C}$, Immunohistochemistry of rab11a in mouse retina shows a punctate distribution in the inner segment with some faint punctate staining in the outer segment. Green, Acetylated $\alpha$-tubulin; red, rab11a; IB, immunoblot. Scale bar, $10 \mu \mathrm{m}$.

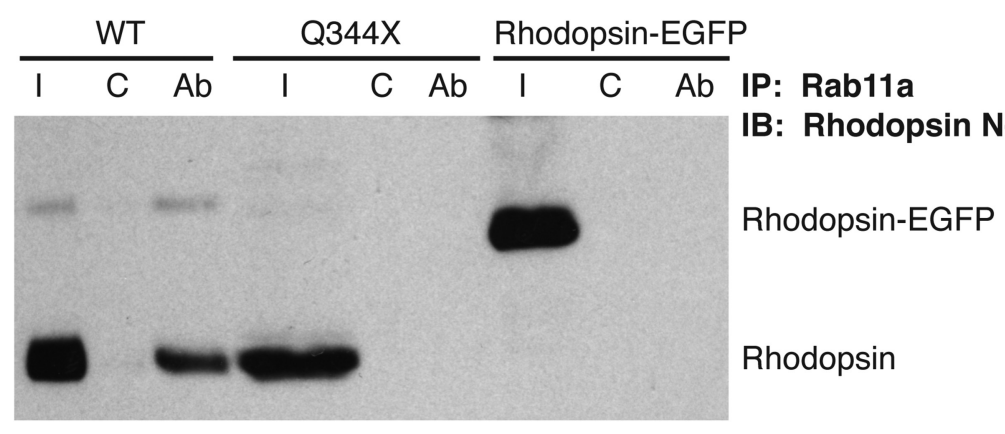

Figure 2. Rab11a binding is dependent on the integrity of the C terminus of rhodopsin. Pull-down experiments using a rab11a antibody show that wild-type rhodopsin can be pulled down by rab11a from retinal extracts but not Q344X or rhodopsin-EGFP. I, Input; C, control IgG antibody wash; Ab, rab11 polyclonal antibody eluate; IP, immunoprecipitation; IB, immunoblot.

\section{Materials and Methods}

Research animals. All animal studies were conducted in compliance with the National Institutes of Health Guide for the Care and Use of Laboratory Animals and approved by the Institutional Animal Care and Use Committee of the University of Alabama at Birmingham.

Knock-in mouse models. Mice with rhodopsin C-terminally fused to EGFP knocked in to the rhodopsin locus ( $h R h o G$ mice) have been previously described (Wensel et al., 2005; Gross et al., 2006). Mice expressing rhodopsin ${ }^{\mathrm{Q} 344 \mathrm{X}}$ have recently been described (Sandoval et al., 2014).

Isolation of rod outer segment membranes and affinity chromatography. Rod outer segment preparations were made from mouse retinas using published methods (Papermaster and Dreyer, 1974; Fotiadis et al., 2004). Rhodopsin was tethered to concanavalin A (ConA)Sepharose using a published method (Litman, 1982) that was modified to use $0.03 \%$ dodecyl maltoside as the detergent (Standfuss et al., 2007). Short peptides corresponding to different regions of the rhodopsin molecule were used to elute bound proteins. Bound proteins were eluted with the peptides EGPNFYVPFS (A5-3-12 peptide) and KETSQVAPA (1D4 peptide). Eluted protein bands were separated by SDS-PAGE and identified using in-gel trypsin digestion and liquid chromatographytandem mass spectrometry.

Retinal extract preparation and immunoprecipitation studies. Retinal extracts for immunoprecipitation were prepared using published methods (Keady et al., 2011). Extracts from three mice were pooled for each experiment. Rab1la polyclonal antibody (71-5300, Life Technologies) was bound to protein G-agarose beads (Life Technologies), and retinal extracts were added to the beads. Following wash steps, proteins were eluted with SDS-PAGE loading buffer. Eluted proteins were analyzed by SDS-PAGE and Western blotting using the N-terminal antibody B6-30N (courtesy of W. Clay Smith and Paul Hargrave, University of Florida, Gainesville, FL). Dot blots were performed essentially as described previously (Tam et al., 2006) using 5\% X. laevis tadpole eye homogenate probing with either rablla polyclonal antibody or with tubulin antibody (A1126, Life Technologies).

GST-rab11 a fusion pull-down assays. Rab11a cDNAs encoding the human wild-type protein S25N and Q70L mutants were gifts from Ben Margolis (University of Michigan, Ann Arbor, MI) (Schlüter et al., 2009). Rab1la cDNAs were subcloned into the pGEX-5X-1 expression vector (GE Healthcare) in frame using BamHI and EcoRI sites. The N124I mutation was introduced by site-directed mutagenesis. GST-rab11 fusion proteins were expressed in BL21 competent bacteria (New England Biolabs) by $2 \mathrm{~h}$ induction at $37^{\circ} \mathrm{C}$ with $0.1 \mathrm{~mm}$ isopropyl $\beta$-Dthiogalactoside. Soluble GST fusion proteins were affinity purified using glutathioneSepharose beads (Thermo Scientific), desalted, and concentrated using Amicon centrifugal filters (EMD Millipore). Fifteen micrograms of GST fusion protein were used per assay. Whole retinal extract or ConApurified mouse rhodopsin were added to the beads for $90 \mathrm{~min}$ at $4^{\circ} \mathrm{C}$. Following wash steps, proteins were eluted from the column with SDS-PAGE loading buffer.

$\mathrm{X}$. laevis transgenesis. Transgenic X. laevis tadpoles were generated by the simplified restriction enzyme mediated integration method (Sparrow et al., 2000). The pXOP0.8 expression vector, a gift from Orson Mortiz (University of British Columbia, BC, Canada) (Tam et al., 2006), was 
modified to insert I-SceI recognition sites near the PciI and AflII sites of the vector to generate pXOP0.8/I2. Plasmids encoding EGFP-fused human rab1la and human rab1la S25N in the pJ $3 \Omega$ backbone were a gift from Wei Guo (University of Pennsylvania, Philadelphia, PA) (Knödler et al., 2010). EGFP-rab1 la constructs were removed from the $\mathrm{pJ} 3 \Omega$ backbone by digestion with SalI and BglII, and inserted into the SalI and NotI sites of pXOP0.8/I2 using a BglII-NotI linker. The Q70L and N124I mutations were generated by site-directed mutagenesis. In preparation for transgenesis, the XOPEGFP-rab1la transgenes were removed from the plasmid backbone by digestion with I-SceI and FspI, and gel purification.

mVenus-microRNA 30 hairpin constructs. The miR-30 knock-down system, where an RNA Pol II promoter drives expression of mVenus (a yellow fluorescent protein) and an miR-30-based hairpin, was designed after a strategy successfully used in zebrafish (De Rienzo et al., 2012) that was based on the characterization of artificial hairpins modeled after human miR-30 by Chang et al. (2013). The human miR-30 recognition sequence and cloning sites were generated via assembly PCR from synthetic oligonucleotides. pN1/I2 and pXOP0.8/I2 were digested with BglII/NotI, and were ligated with the BamHI/BsrGI fragment of mVenus and the BsrGI/NotI miR-30 fragment to produce $\mathrm{pN} 1 / \mathrm{I} 2 \mathrm{mVmiR} 30$ and pXOP0.8/I2 mVmiR30. Hairpins were generated using the pSM2 algorithm (http://cancan.cshl.edu/RNAi_central/RNAi.cgi?type $=$ shRNA), and were produced by PCR amplifying the designed oligo with the primers CAGAAGGCTCGAGAAGGTATATTGCTGTTGACAGTGAGCG and CTAAAGTAGCCCCTTGAATTCCGAGGCAGTAGGCA, digesting the product with XhoI and EcoRI, and ligation into the corresponding sites in the expression vectors. The hairpin directed against firefly luciferase was based on luc1309 (Silva et al., 2005).

Immunohistochemistry. Enucleated eyes from 3-week-old mice of either sex were placed in $4 \%$ paraformaldehyde in $0.1 \mathrm{M} \mathrm{PBS,} \mathrm{pH} 7.4$ (PBS) for $4 \mathrm{~h}$ at room temperature. Following incubation overnight in $30 \%$ sucrose in PBS at $4^{\circ} \mathrm{C}$, eyes were embedded in Tissue-Tek O.C.T. (Sakura Finetek USA), frozen, and sectioned at $12 \mu \mathrm{m}$ intervals using a cryomicrotome. For tadpole sections, whole tadpoles of either sex were fixed overnight in $4 \%$ paraformaldehyde at $4^{\circ} \mathrm{C}$, then eyes were removed and processed as above for mouse eyes. Wheat germ agglutinin (Life Technologies) conjugated to Alexa Fluor 555 or Alexa Fluor 647 was used in some experiments to counterstain the outer segments. For staining on mouse sections using rablla antibody, sections were treated with heat-induced antigen retrieval. This was accomplished by boiling samples in $10 \mathrm{~mm}$ sodium citrate and $0.05 \%$ Tween, pH 6.0 for $1 \mathrm{~h}$, cooling to room temperature for $20 \mathrm{~min}$. Images were collected on a Zeiss LSM 510 Meta confocal microscope with a $63 \times$ oil-immersion objective, or on a PerkinElmer UltraVIEWERS 6FE-US spinning disk confocal attached to a Nikon TE2000-U with a $100 \times$ oil-immersion objective. Simultaneous imaging of EGFP and mVenus was achieved by using spectral unmixing with the LSM 510 Meta.

Statistical analyses. All statistical analyses were performed using SPSS software (IBM). All biochemistry experiments were performed at least three times with similar results. For all immunohistochemical or transgenic studies where an $n$ is reported, the $n$ represents the number of separate animals. For transgenic studies, animals with gross morphologic abnormalities were excluded from analyses, otherwise no method to exclude outliers was used. Given the nature of X. laevis transgenesis, randomization did not apply. Depending on the experiment, either

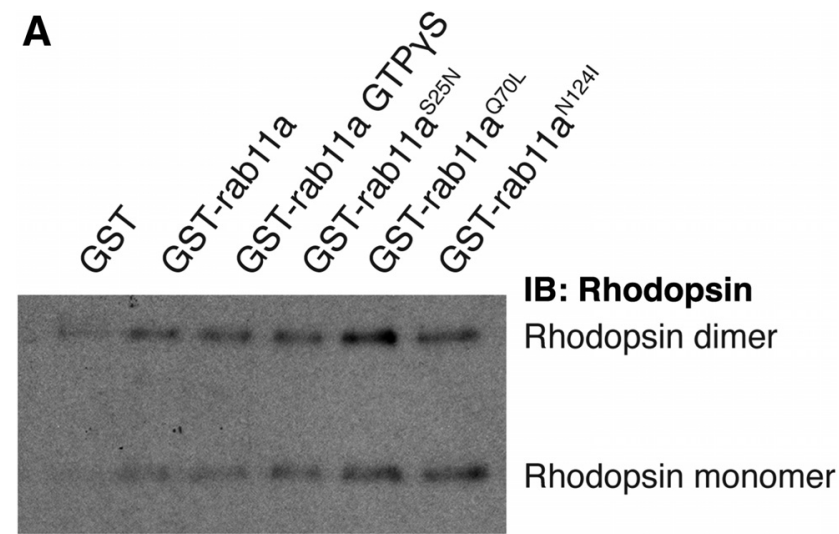

\section{B}

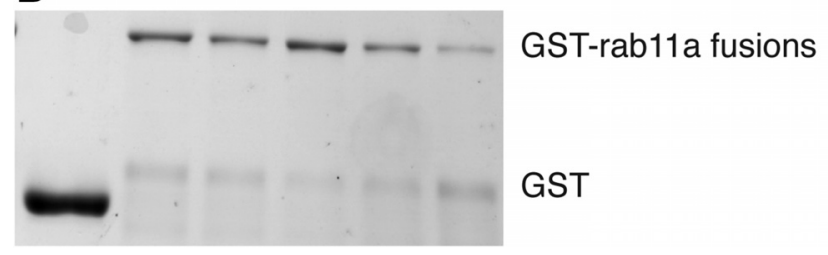

Figure 4. Rab11a binds rhodopsin directly and independently of nucleotide binding status. GST fusions of rab11a and mutants were assayed for their ability to pull down purified native rhodopsin. All rab11a mutants tested were bound to purified rhodopsin. Across repeated experiments, no rab11a mutant had an increased or decreased affinity for rhodopsin relative to wild-type rab11a. $A$, Western blot of purified rhodopsin pull-down experiments. $\boldsymbol{B}$, Coomassie gel of purified GST-rab11a fusions. IB, immunoblot.

Student's unpaired $t$ test or ANOVA with Tukey's HSD test for post hoc comparisons was used. Analysis of all TUNEL datasets by Kruskal-Wallis nonparametric ANOVA with post hoc comparisons yielded identical conclusions, assuming significance at $p<0.05$. 
A
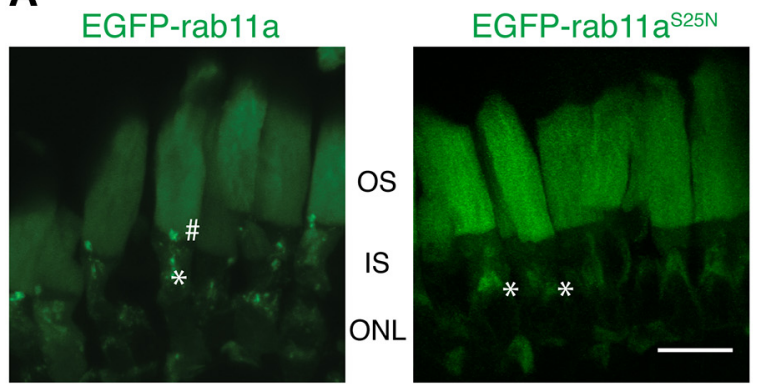

EGFP-rab11a Q70L
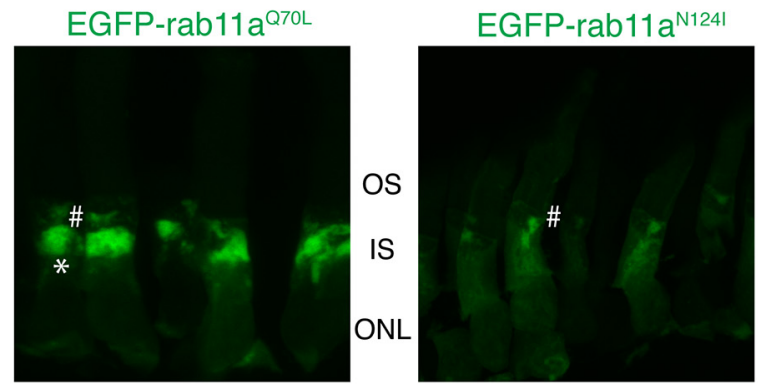

B

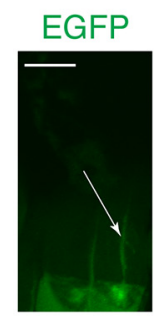

rab11a
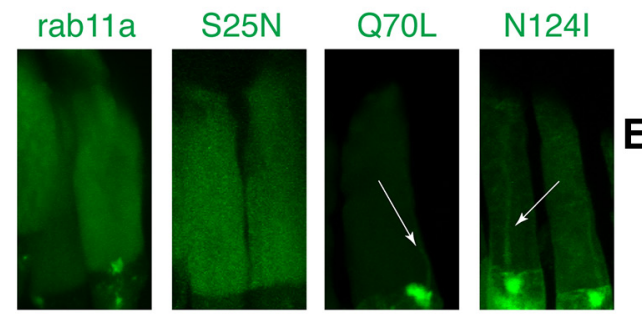

C
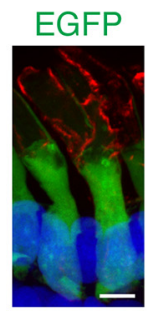

rab11a
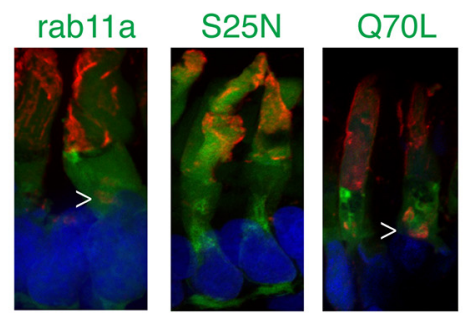

N124I

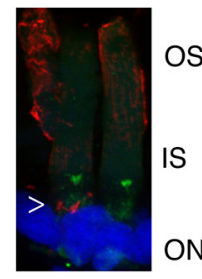

Figure 5. Subcellular localization of EGFP-rab11a and mutants in transgenic X. laevis frog photoreceptors. $\boldsymbol{A}$, Representative images of EGFP-tagged rab11a variants in X. laevis photoreceptors. EGFP-rab11a is present diffusely in the outer segment, as is the S25N mutant. The Q70L and N124I variants primarily localize in the inner segment. \#, Putative recycling endosome localization; *, Golgi cells. Scale bar, $10 \mu \mathrm{m}$. B, Outer segment distributions of the rab11a constructs and soluble EGFP. Images were taken with higher-intensity settings to highlight the axoneme. EGFP, rab11a ${ }^{070 \mathrm{~L}}$, and rab11 ${ }^{\mathrm{N} 1241}$ are all present in an axonemal distribution. C, Rhodopsin staining among tadpoles expressing EGFP or EGFP-tagged rab11a constructs. Arrowheads indicate staining in the inner segment. $\boldsymbol{D}$, The relative fluorescence of each mutant for the $0 S$, IS, nucleus, and synapse was compared with that of EGFP-rab11a ( $n=5-9$ per mutant). The $0 S$ fluorescent signal was significantly increased for the $525 \mathrm{~N}$ mutant and significantly decreased for the Q70L and N124I mutants (one-way ANOVA: $F_{(3,22)}=18.34, p<0.001$; Tukey's HSD test: for S25N, $p=0.023$; for $\mathrm{Q70L}, p=0.018$; for $\mathrm{N} 124 \mathrm{I}, p=0.026$ ). The IS fluorescent signal was significantly increased for the $\mathrm{Q} 70 \mathrm{~L}$ mutant relative to rab11a (one-way ANOVA $F_{(3,22)}=12.59, p<0.001$; Tukey's HSD test, $p<0.001$ ). The nuclear fluorescent signal was significantly increased for the Q70L and N124I mutants relative to rab11a $\left(F_{(3,22)}=21.40, p<0.001\right.$; Tukey's HSD test: for Q70L, $p=0.04$; for $\mathrm{N} 124 \mathrm{I}, p<0.001)$. No significant differences in synapse fluorescent signal were observed $\left(F_{(3,22)}=3.20, p=0.043\right.$; but for all Tukey's HSD test comparisons, $p>0.05)$. ${ }^{*} p<0.05,{ }^{* *} p<0.01,{ }^{* * *} p<0.001$. Error bars represent the SEM. E, Dot blots showing the relative content of rab11a in mouse ROS preparation versus total retinal extract (RE). Green, EGFP; red, rhodopsin; blue, DRAQ5.

\section{Results}

Affinity chromatography reveals rab11a as a rhodopsinbinding protein in mouse photoreceptors

To identify proteins binding to the $\mathrm{C}$ terminus of rhodopsin, we conducted affinity chromatography studies using rod outer seg- ment preparations from wild-type mice. To identify C-terminal binding partners, it was essential to tether rhodopsin to the affinity column by its $\mathrm{N}$ terminus. We used the nonionic detergent dodecylmaltoside, in which rhodopsin is structurally and functionally stable, to solubilize retinas taken from knock-in or wild-type mice followed by incubation with ConASepharose beads to bind the Asn-linked sugars present on the $\mathrm{N}$ terminus of rhodopsin. After wash steps with a peptide corresponding to the $\mathrm{N}$ terminus of rhodopsin, addition of a peptide corresponding to the $\mathrm{C}$ terminus of rhodopsin eluted four proteins of low molecular weight (Fig. 1A). Three of these proteins could be identified by mass spectroscopy: ADP/ ATP translocase 2 (ant 2), rab1la, and $\operatorname{PDE} 6 \delta$ (also known as $\operatorname{PrBP} / \delta$ ). The identity of rab11a was confirmed by Western blot analysis (Fig. 1B). Immunohistochemistry for rab11a on sections of mouse retina revealed a strong punctate appearance in the rod inner segment with weak signal in the outer segment (Fig. 1C).

Ant2 has been identified in one proteomic study of rod disks (Panfoli et al., 2008), but, as a mitochondrial protein, is generally assumed to be a contaminant and has been excluded from other proteomic studies of the outer segment (Liu et al., 2007). Rab11a has been identified in frog rod cell extracts (Mazelova et al., 2009). Interestingly, rab1la and PDE6 $\delta$ have been shown to bind directly to other GPCRs, including the $\beta$-adrenergic receptor and the human prostacyclin receptor (Wikström et al., 2008). Unlike the prostacyclin receptor, rhodopsin lacks a farnesyl or geranylgeranyl modification, so it is unlikely that PDE6 $\delta$ binds to it directly. Because rab11a is known to be geranylgeranylated, it is possible that PDE6 $\delta$ is associated indirectly with rhodopsin through a direct interaction with rab1la. Although no peptides were identified from the $\sim 18 \mathrm{kDa}$ band, it is of the correct size to be Arf4, which is also known to bind rhodopsin (Mazelova et al., 2009). We chose to focus on the rab11arhodopsin interaction to examine how rablla function regulates rhodopsin trafficking.

\section{Rhodopsin C-terminal mutations} abrogate the interaction with rab11a

We sought to assay whether mutations in the $\mathrm{C}$ terminus of rhodopsin could alter the interactions with rab11a. To do this, we isolated retinas from mice with homozygous knock-in mutations in rhodopsin. Detergent extracts of these preparations were passed over an anti-rablla immunoaffinity column. Interestingly, wild-type rhodopsin 
could be pulled down with rab11a, but rhodopsin ${ }^{\mathrm{Q} 344 \mathrm{X}}$ and rhodopsin-EGFP could not (Fig. 2, Ab lanes).

To examine the interaction of rhodopsin and rablla in situ, we used the proximity ligation assay (PLA), an immunodetection method used to identify two proteins that are close in space with high sensitivity and specificity. The monoclonal rhodopsin antibody $\mathrm{B} 6-30 \mathrm{~N}$ and a commercial polyclonal rab1la antibody were used. In agreement with our biochemical studies, the PLA interaction signal in wild-type retinas was detected in the inner and outer segments, while the signal was significantly reduced in retinal sections from mice homozygous for rhodopsin Q344X (Fig. 3).

The rhodopsin-rab11a interaction is direct and does not depend on the nucleotide binding state of rab1 1a Since the nucleotide-binding status of rab1 1a affects its conformation and function (Pasqualato et al., 2004), we investigated whether the nucleotide-binding status of rablla affected its interaction with rhodopsin. We used GST fusion proteins of rab1la to pull down rhodopsin from whole retinal extracts or preparations of purified rhodopsin. The following mutant GST fusions were made: GSTrab11a ${ }^{\text {S25N }}$, preferentially in the GDP-bound state; GST-rab11a ${ }^{\mathrm{Q70L}}$, preferentially in the GTP-bound state; and GST-rab11a ${ }^{\text {N124I }}$, which binds neither GDP nor GTP (Ullrich et al., 1996; Satoh et al., 2005). The Q70L mutation is commonly considered to be constitutively active, while the S25N and N124I mutation are commonly considered to be dominant negative. As previously reported (Wang et al., 2012), GSTrab1la pulled down purified rhodopsin, indicating that the interaction is direct (Fig. 4). GST-rab11 a treated with the nonhydrolyzable GTP analog GTP $\gamma$ S could also pull down purified rhodopsin. Interestingly, the nucleotide binding status had no effect on its rhodopsin interaction, as all fusion proteins tested bound rhodopsin (Fig. 4). Over several trials, we did not detect a consistent change in rhodopsin binding affinity among the rab11a mutants tested in our replicates of this experiment.

\section{Expression of EGFP-rab11a fusions in X. laevis} photoreceptors reveals the importance of nucleotide cycling for proper localization and function

To examine the effects of introducing mutant rab1la proteins on photoreceptor health and function, we expressed EGFP-tagged mutants of rab11a in X. laevis tadpoles. The EGFP-rab11a signal was detected in the inner segment, with an increased fluorescence signal near the inner segment-outer segment junction (Fig. 5A). In addition, EGFP-rab1la was present diffusely in the outer segment. The presence of EGFP-rab1la in the outer segment was

C
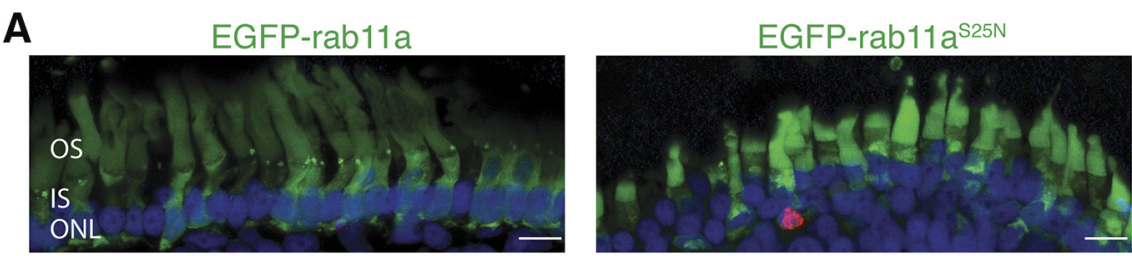

EGFP-rab11aQ70L

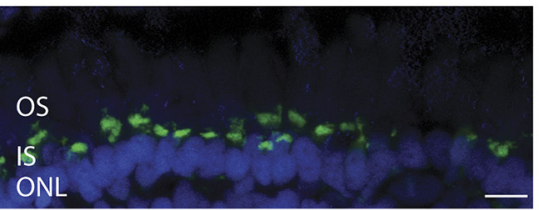

EGFP-rab11a $a^{\mathrm{N} 124 \mathrm{I}}$

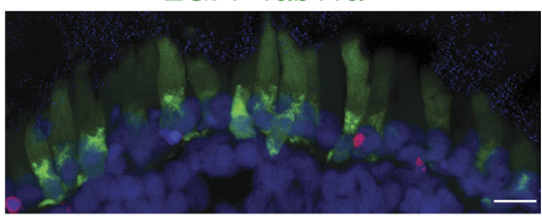

TUNEL DRAQ5
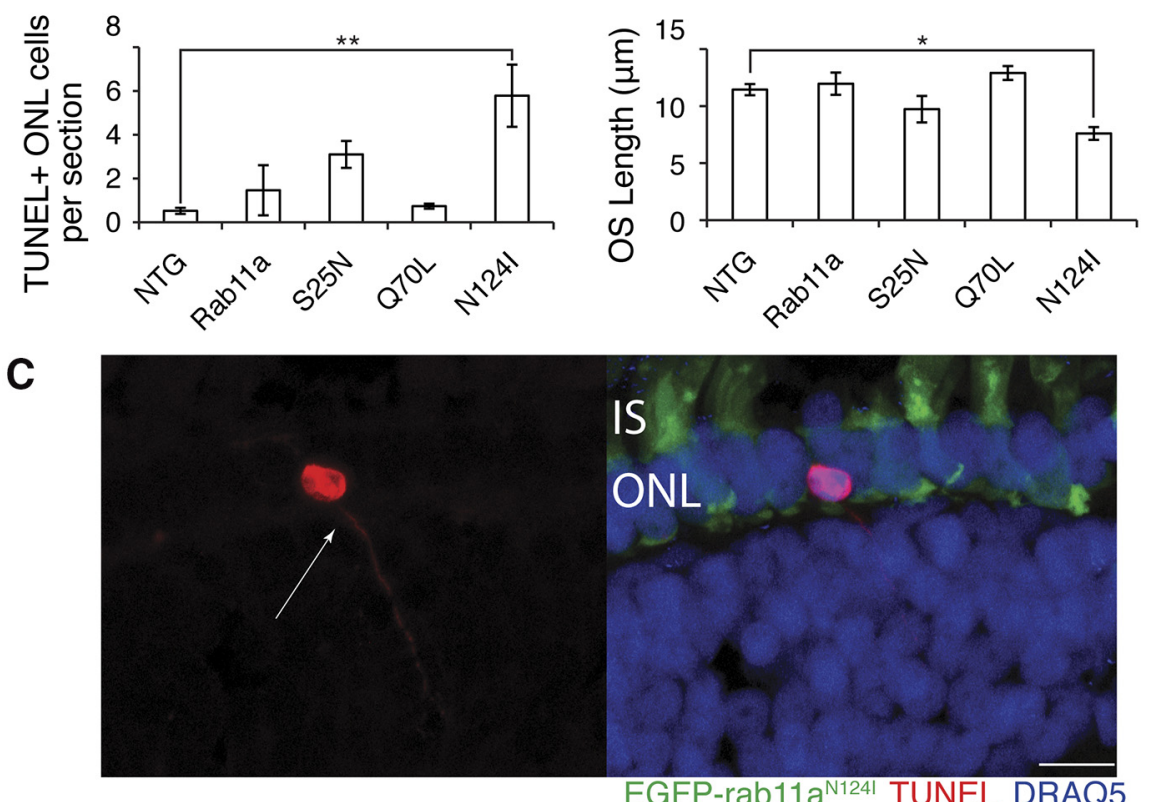

ure 6. Quantification of TUNEL staining and OS length among the rab11a constructs. EGFP-rab11a-expressing tadpoles and nontrangenic controls (data not shown) were stained for TUNEL, to detect dying cells, and with WGA (data not shown), to measure outer segment length. $\boldsymbol{A}$, Representative images of EGFP-rab11a tadpole sections stained for TUNEL. $\boldsymbol{B}$, EGFP-rab11a ${ }^{\text {N1241 }}$ expressing tadpoles had a significant increase in TUNEL-positive cells per section ( $n=5$ per group; one-way ANOVA: $F_{(4,20)}=$ $6.383, p=0.002$; Tukey's HSD test: for N124I compared with nontransgenic animals, $p=0.003$; for all other comparisons to nontransgenic animals, $p>0.05$ ). These animals also had significantly decreased 0 S length relative to nontransgenic controls ( $n=6$-8 per group; one-way ANOVA: $F_{(4,29)}=6.01, p=0.001$; Tukey's HSD test: for N124l, $p=0.035$; for all other comparisons to nontransgenic animals, $p>0.05$ ). ${ }^{*} p<0.05,{ }^{* *} p<0.01$. C, TUNEL-positive processes (arrow) projecting from the ONL into the inner retina were observed in EGFP-rab11a ${ }^{\mathrm{N} 1241}$-expressing tadpoles. Although TUNEL-positive processes from inner retinal cells could be observed in all transgenic animals and nontransgenic controls, the only TUNEL-positive processes extending from nuclei in the ONL were found in those animals expressing EGFP-rab11a ${ }^{\mathrm{N} 1241}$. Green, EGFP; red, TUNEL; blue, DRAQ5. Error bars represent the SEM. Arrows depict regions in the inner segment putatively containing Golgi apparatus. Scale bar, $10 \mu \mathrm{m}$.

unexpected as rab1la does not appear to enter the cilium in cultured cells (Babbey et al., 2010). Interestingly, in rods, the expression of EGFP-rab11 $\mathrm{a}^{\mathrm{S} 25 \mathrm{~N}}$ resulted in a distribution in which the majority of the fusion protein localized to the outer segment, with the remainder in the Golgi and synaptic regions, while the bright concentration at the inner segment-outer segment junction was lost (Fig. 5A). The expression of EGFP-rab11a ${ }^{\text {Q70L }}$ resulted in a nearly opposite distribution, with greatly reduced outer segment localization but a high concentration in the inner segment, visible as a bright region at the inner segment-outer segment boundary and a bright region proximal to the myoid region (Fig. 5A). OS localization of EGFP-rab11a ${ }^{\text {Q70L }}$ was largely restricted to the axoneme (Fig. 5B). Expression of EGFP-rab1 1a ${ }^{\text {N124I }}$ revealed a pri- 

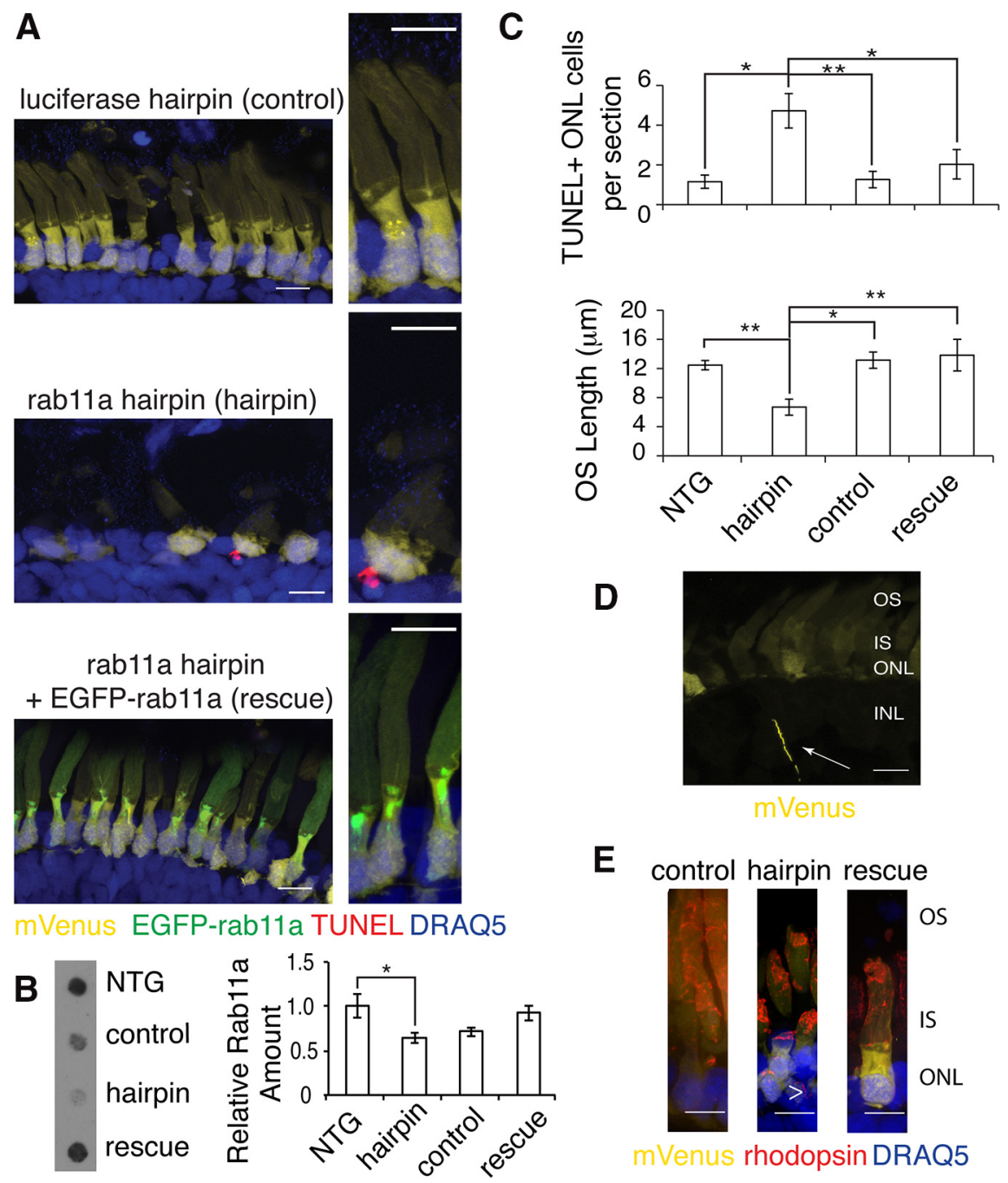

Figure 7. Expression of hairpin against rab11a leads to ectopic process formation, reduction in outer segment length, and increased photoreceptor death. $\boldsymbol{A}$, Representative images of tadpoles expressing various constructs. Yellow, mVenus; green, EGFP-rab11a; red, TUNEL; blue, DRAQ5. $\boldsymbol{B}$, Representative dot blots from whole tadpole eye showing rab11a expression changes with hairpin expression. Expression was normalized to tubulin (data not shown). Hairpin-expressing tadpoles had a significant $35.5 \%$ reduction in total eye rab11a ( $n=5-8$ per group; one-way ANOVA, $F_{(3,22)}=4.038, p=0.02$; Tukey' HSD test for nontransgenic versus hairpin, $p=0.038$. C, Quantification of TUNEL-positive cells and OS length. Rods expressing a hairpin against firefly luciferase had normal morphology. Rods expressing a hairpin against rab11a had shorter outer segments and significantly increased numbers of TUNEL-positive cells per section. Coexpression of EGFP-rab11a resistant to the hairpin rescued the effects. TUNEL-positive cells ( $n=8-14$ per group; one-way ANOVA, $F_{(3,39)}=6.031, p=0.002$; Tukey's HSD test: for rab11a hairpin versus nontransgenic animals, $p=0.001$; for rab11a hairpin versus luciferase hairpin, $p=0.009$; for rab11a hairpin versus rescue, $p=0.048$; all other comparisons, $p>0.05$ ). OS length ( $n=6-14$ per group): one-way ANOVA: $F_{(3,34)}=6.858, p=0.001$; Tukey's HSD test: for rab11a hairpin versus nontransgenic animals, $p=0.006$; for rab11a hairpin versus luciferase hairpin, $p=$ 0.017; for rab11a hairpin versus rescue, $p=0.002$; all other comparisons, $p>0.05$. D, TUNEL-positive processes (arrow) projecting from the $0 \mathrm{NL}$ into the inner retina were observed in rab11a hairpin-expressing tadpoles. Yellow, mVenus. $\boldsymbol{E}$, Rhodopsin staining of tadpoles expressing hairpin constructs. Arrowheads indicate inner segment or nuclear layer staining of rhodopsin. Yellow, mVenus; red, rhodopsin; blue, DRAQ5. Scale bars, $10 \mu \mathrm{m} .{ }^{*} p<0.05,{ }^{* *} p<0.01,{ }^{* * *} p<0.001$.

marily inner segment distribution and a concentration at the inner segment-outer segment boundary, but an axonemal outer segment distribution (Fig. 5A,B). Immunohistochemistry for rhodopsin (Fig. 5C) showed a weak rhodopsin signal in the inner segments of rab1la-, rab11a ${ }^{\mathrm{Q}^{70 L}}$, and rab11a ${ }^{\mathrm{N} 124 \mathrm{I}}$-expressing tadpoles. Detection of rhodopsin in the inner segments in these rods could be due to Golgi localization, which has been described previously in this system (Mazelova et al., 2009). The fluorescent signal for the OS, IS, nucleus, and synapse relative to the entire cell was compared across all rab11a constructs (Fig. 5D). Relative to EGFP-rab11a, the OS fluorescent signal was significantly in- creased for the $\mathrm{S} 25 \mathrm{~N}$ mutant and significantly decreased for the Q70L and N124I mutants, while the IS fluorescent signal was significantly increased for the Q70L mutant. The nuclear fluorescent signal was significantly increased for the Q70L and N124I mutants relative to rab11a. No significant differences in synaptic fluorescent signal were observed. The relative amount of rablla expression was compared between isolated mouse rod outer segments and whole retinal extract (Fig. $5 E)$. In agreement with transgenic rods (Fig. $5 A-C$ ), we found the rabl la signal in isolated rod outer segments from dot blot analyses (Fig. 5E).

To assess for cell death or dysfunction, sections from transgenic tadpoles were stained for TUNEL to detect dying cells (Fig. 6A) or with wheat germ agglutinin to measure OS length (data not shown). TUNEL-positive cells were counted along the length of an entire retinal section, whereas only the OS length of central rods was measured. Rab1la-expressing tadpoles were compared with nontransgenic controls. Comparison of outer-segment length in the central retina revealed a significant decrease in the outer segment length of EGFP-rab11 ${ }^{\mathrm{N} 124 \mathrm{I}}$-expressing transgenics relative to nontransgenic animals, whereas no significant difference was observed for the other constructs (Fig. $6 A, B)$. EGFP-rab11 ${ }^{\mathrm{N} 124 \mathrm{I}}$-expressing transgenic animals were also found to have a significantly increased number of TUNEL-positive cells per section relative to nontransgenic controls. TUNEL-positive processes were occasionally seen protruding from the outer nuclear layer $(\mathrm{ONL})$ into the inner retina of EGFP-rab11 $\mathrm{a}^{\mathrm{N} 124 \mathrm{I}}$-expressing tadpoles (Fig. 6C).

\section{Knockdown of rab1la in X. laevis rods leads to ectopic process formation and retinal degeneration}

Having shown cytotoxic effects and ectopic process formation upon expression of a dominant-negative rab11a in $X$. laevis rods, we were curious as to the effects of removing rab1la from these cells. To accomplish this, we devised a construct where mVenus and a human miR-30-based hairpin could be coexpressed from the Xenopus opsin promoter, turning on expression only in rod cells of the retina when rhodopsin is first expressed. Photoreceptors expressing the hairpin would thus also be labeled by soluble mVenus. We examined animals expressing these constructs at 14 and $28 \mathrm{~d}$ postfertilization (DPF) as we did not know whether the effects of hairpin expression would be readily apparent at $14 \mathrm{DPF}$ and preliminary experiments suggested a greater effect at later ages. Sections from these animals were subjected to the same OS length analysis and TUNEL staining as the rab1la mutant-expressing tadpoles. Our analysis by 


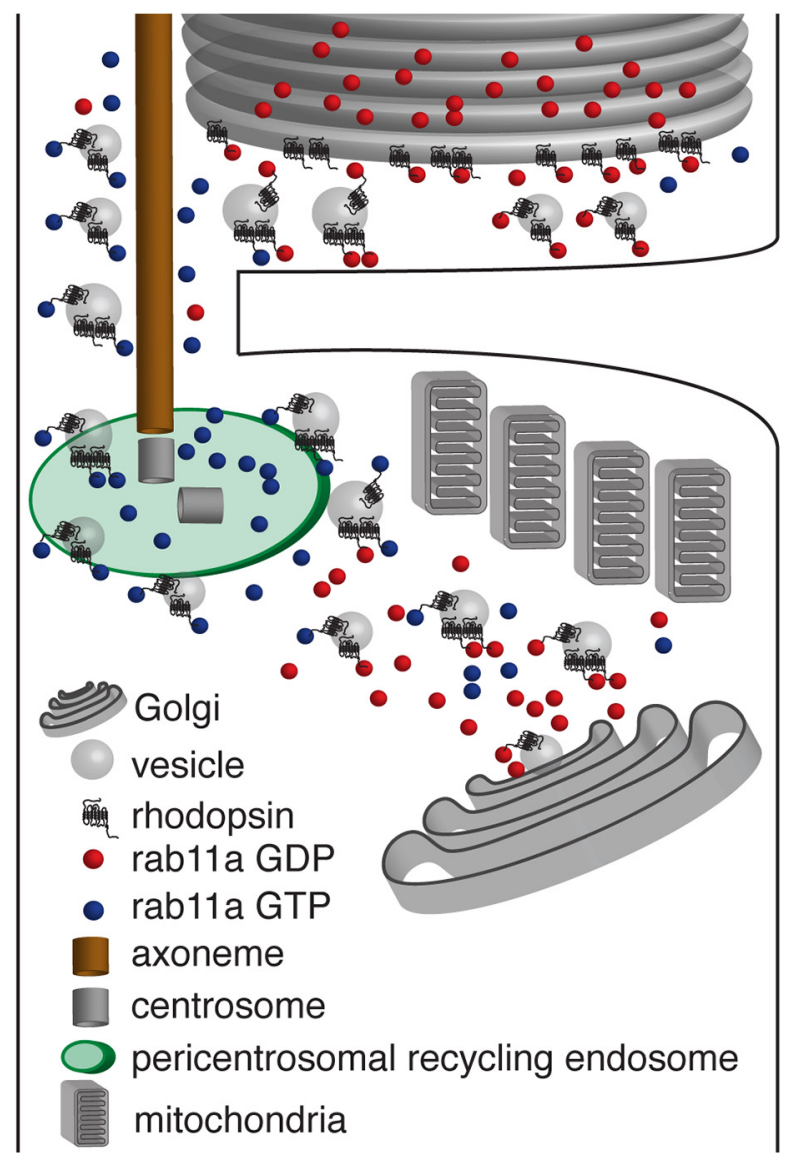

Figure 8. Schematic representation of the rab11a recycling endosome in rod photoreceptors. Rab11a in the GDP-bound form associates with rhodopsin in the IS near the Golgi and also in the outer segment disks. Rab11a in the GTP-bound form is associated with rhodopsin around the centrosome and extending up the axoneme. The rab11a that remains associated with disks is in the GDP-bound form.

two-way ANOVA did not detect an effect of time or an interaction between time and expression constructs, so both time points were combined for analysis. The expression of a hairpin directed against $X$. laevis rab11a mRNA led to OS length reduction and an increase in cell death as measured by TUNEL (Fig. 7A-C). These effects were not seen with the expression of a control hairpin against firefly luciferase or when the hairpin-resistant EGFPrablla construct was coexpressed with the rab1la hairpin. The bright concentration of EGFP-rab1 1a localized to the base of the mVenus-labeled axoneme in the rescue animals (Fig. 7A). Hairpin expression reduced rab11a levels by $35.5 \%$ on average in protein extracts prepared from whole tadpole eyes (Fig. $7 B$ ). Reminiscent of the TUNEL-positive processes seen in tadpoles expressing EGFP-rab11 $\mathrm{a}^{\mathrm{N} 124 \mathrm{I}}$, mVenus-positive processes occasionally could be seen extending into the inner nuclear layer with expression of the rab11a hairpin (Fig. 7D). To monitor rhodopsin localization, retinal sections expressing hairpins were stained with the rhodopsin N-terminal antibody B6-30N (Fig. 7E). Rhodopsin staining was detected in the nuclear layer of hairpin-expressing rods (Fig. 7E, arrowhead).

\section{Discussion}

Our experimental approach identified rab11a as part of the major complex associated with the C-terminal targeting sequence of rhodopsin in mouse retina. Discounting the mitochondrial ant2 protein as an artifact, all of the proteins detected are known com- ponents of outer segment trafficking. A role for rab1la in rhodopsin trafficking has been reported in Drosophila melanogaster (Satoh et al., 2005) and frogs (Mazelova et al., 2009), but the direct interaction of rab1la and, specifically, the $\mathrm{C}$ terminus of the rhodopsin molecule has not previously been detected in vertebrate photoreceptors. The fact that this interaction is disrupted by mutations in the $\mathrm{C}$ terminus of rhodopsin that lead to defects in outer segment formation and retinal degeneration, including rhodopsin-EGFP and rhodopsin ${ }^{\mathrm{Q} 344 \mathrm{X}}$, suggests that the loss of rab11a binding may be the main cause of these defects.

Two other rab proteins, rab6 (Deretic and Papermaster, 1993; Shetty et al., 1998) and rab8 (Deretic et al., 1995; Moritz et al., 2001), have been implicated in rhodopsin trafficking in D. melanogaster and frog photoreceptors. Our results here expand on these findings to suggest a role for rab1la in disk formation in addition to Golgi-to-cilium trafficking. Expression of dominantnegative rab11 $\mathrm{a}^{\mathrm{N} 124 \mathrm{I}}$ and knockdown of rab1la both led to the formation of ectopic processes, mimicking the expression of $X$. laevis rhodopsin ${ }^{\mathrm{Q} 350 \mathrm{X}}$ in Xenopus rods and dysmorphic rods seen in human retinitis pigmentosa (Fariss et al., 2000; Tam et al., 2006). Given the small amount of rhodopsin mislocalization seen in surviving rods in the rab11 $\mathrm{a}^{\mathrm{N} 124 \mathrm{I}}$ or rab11a hairpin-expressing rods, the following two possible explanations arise: first, due to the mosaic nature of the transgenic system, it is possible that the remaining cells express enough rab1 la to transport rhodopsin to the outer segment; or second, that there is sufficient redundancy in trafficking proteins that, while most rhodopsin is trafficked properly, there is still enough mislocalization to induce cell death. This suggests that there are other trafficking interactions that direct rhodopsin into these ectopic processes in the absence of rab11a. Indeed, alternate trafficking pathways that recognize sites in the proximal $\mathrm{C}$ terminus have recently been identified (Lodowski et al., 2013).

Although it is known that rhodopsin is fully functional as a monomer (Bayburt et al., 2011), there is evidence for rhodopsin dimerization within rod outer segments (Knepp et al., 2012). The question of whether rhodopsin traffics as a dimer, as has been proposed (Sung et al., 1994; Li et al., 1996; Green et al., 2000; Concepcion and Chen, 2010), is important for understanding the pathogenesis of retinal degeneration in patients with one wildtype allele and one dominant mutant allele. We did not measure the stoichiometric ratio of rhodopsin and rab11a in complex, so our data do not argue for either monomeric or dimeric trafficking. Therefore, we cannot exclude the possibility that C-terminal mutant rhodopsin may form dimers with wild-type rhodopsin leading to mislocalization. However, it seems likely that rhodopsin-containing post-Golgi vesicles will contain molecules produced from both alleles of the rhodopsin gene, even if a given vesicle may vary in its content of wild-type and mutant rhodopsin. Since the rab11a-dependent localization signal at the distal $\mathrm{C}$ terminus appears to dominate over alternative trafficking signals, we hypothesize that vesicles with high mutant rhodopsin content mislocalize. This is supported by findings from several laboratories in which the relative expression of mutant rhodopsin dictates whether significant degeneration is seen (Concepcion et al., 2002; Concepcion and Chen, 2010; Price et al., 2012). Thus, it is likely that the relative complement of rab11a binding sites on the vesicle, not the monomeric or dimeric form of rhodopsin, determines proper or improper localization.

Our data from transgenic $X$. laevis show rab11a diffusely present in the outer segment and concentrating in a region near the inner segment-outer segment boundary. Rab1la is not reported 
to localize to the cilium in cultured ciliated cells, yet we detect localization of the transgenically expressed EGFP fusion protein in the outer segment. Published immunohistochemistry for rab11a does not show any appreciable outer segment staining (Grossman et al., 2011). It is appreciated that antibodies cannot penetrate the outer segment well; immunofluorescence for rhodopsin typically shows only the outer plasma membrane being labeled (Chuang et al., 2007). The discrepancy between immunohistochemistry and transgenic protein localization may be due to this factor or other steric inaccessibility of the trafficking complex. We detected rhodopsin in mouse rod OS (ROS) preparations at a lesser concentration than that for the whole retinal extract (Fig. 5E).

The observed distribution of rab1la and the various mutants can be explained by comparing the localization in rod cells with the localization in other cell types. The distal inner segment contains the basal body (Muresan et al., 1993), so it is reasonable to conclude that the observed EGFP-rab1la concentration at this site corresponds to the concentration of rabl1a at a pericentrosomal recycling endosome similar to those described in cultured cells (Ullrich et al., 1996; Ren et al., 1998; Knödler et al., 2010). Additionally, rab1 1 a has recently been described to associate with appendages of the mother centriole in a GTP-dependent manner, which could be important as the ciliary axoneme arises from the mother centriole (Hehnly et al., 2012). A pericentrosomal recycling endosome as such has not been directly studied in photoreceptors but has been hypothesized to exist (Sung and Chuang, 2010). This conclusion would imply that the middle rhodopsin-containing bulk of the disk is, for the purposes of rab11a, topologically identical with the plasma membrane of the cell. Rabl1a-dependent trafficking of rhodopsin to the outer segment is thus a special case of a recycling or sorting endosome. It has been observed that the outer segment of rods functions as a "default" pathway for integral membrane proteins (Baker et al., 2008). The reason for the outer segment being the default membrane protein destination may be due to rablladependent trafficking of membrane protein cargo to the outer segment disks. Thus, the loss of proper rhodopsin trafficking due to truncation mutations could have a cascade effect, preventing the assembly of other outer segment components.

It has been described that GTP-rab11a is the form that associates with the recycling endosome (Ullrich et al., 1996; Ren et al., 1998); indeed, EGFP-rab11a and EGFP-rab11a ${ }^{\text {Q70L }}$ both appear in the putative pericentrosomal recycling endosome location, whereas EGFP-rab11a ${ }^{\text {S25N }}$ does not. EGFP-rab11a ${ }^{\text {N124I }}$ also appears in this location but as there is a cytoplasmic space between the mitochondria in this location (Peet et al., 2004) it is unclear whether the EGFP-rab11 $\mathrm{a}^{\mathrm{N} 124 \mathrm{I}}$ is accumulating in this space or whether it is associating with the putative rab1la recycling endosome. Expression of the EGFP-rab11 ${ }^{\mathrm{N} 124 \mathrm{I}}$ mutant, which does not appear to associate with disks, increased rhodopsin staining in the inner segment and was the only mutant to cause a statistically significant reduction in outer segment length and a statistically significant increase in photoreceptor death as measured by TUNEL staining. Since this mutant binds rhodopsin, it seems likely that an interaction with another trafficking component must be deficient. The original article (Duman et al., 1999) describing the N124I mutation hypothesized that its dominantnegative effect might be due to it acting as a sink for the rablla guanine nucleotide exchange factor (GEF). The rab1la GEF was recently identified in D. melanogaster as the protein Crag, analogous to DENND4a in mammals, which interacts with rablla during the transport of Rh1 to the rhabdomere (Xiong et al.,
2012). Future work will have to study whether DENND4a plays a similar role in vertebrates and whether it localizes to this same pericentrosomal compartment.

The hypothesis that a rab11a recycling endosome is involved in rhodopsin trafficking is most consistent with a model in which rhodopsin traffics continuously in vesicular form until arriving at the outer segment disks, as has been recently proposed (Sung and Chuang, 2010; Fig. 8). A recently published study (Gilliam et al., 2012) using cryo-electron tomography has shown the presence of many vesicles in the pericentrosomal region of photoreceptors and near the connecting cilium. One possibility is that rab1 $1 \mathrm{a}$ and its effectors mediate transport to the recycling endosome intraflagellar transport, or that another microtubule-dependent process mediates transport though the connecting cilium, then rab11a and its effectors mediate fusion of rhodopsin-laden vesicles with the nascent disks (Fig. 8). A similar process, where a microtubule-dependent step separates two rab11a-dependent steps, has been proposed for the transport of the rab11a cargo langerin from the recycling endosome to the plasma membrane in association with the rab1 la effectors rab11fip 2 and myosin $\mathrm{Vb}$ (Gidon et al., 2012). There is evidence for actin filaments at the site of disk formation (Chaitin and Burnside, 1989; Gilliam et al., 2012), so the hypothesis that rab11a and myosin Vb mediate the final assembly of rhodopsin vesicle and disk is worthy of further study. Perhaps tellingly, there is a study on Rh1 trafficking to rhabdomeres in D. melanogaster that outlines such a process $(\mathrm{Li}$ et al., 2007).

While the precise details of the mechanisms by which rhodopsin moves from post-Golgi rhodopsin vesicles to the disks remain to be determined, our results suggest that rab11a binding directly to the C-terminal targeting sequence of rhodopsin, which is independent of the guanine nucleotide bound, is likely to play an important role at multiple steps throughout the entire pathway.

\section{References}

Babbey CM, Bacallao RL, Dunn KW (2010) Rab10 associates with primary cilia and the exocyst complex in renal epithelial cells. Am J Physiol Renal Physiol 299:F495-F506. CrossRef Medline

Baker SA, Haeri M, Yoo P, Gospe SM 3rd, Skiba NP, Knox BE, Arshavsky VY (2008) The outer segment serves as a default destination for the trafficking of membrane proteins in photoreceptors. J Cell Biol 183:485-498. CrossRef Medline

Bayburt TH, Vishnivetskiy SA, McLean MA, Morizumi T, Huang CC, Tesmer JJ, Ernst OP, Sligar SG, Gurevich VV (2011) Monomeric rhodopsin is sufficient for normal rhodopsin kinase (GRK1) phosphorylation and arrestin-1 binding. J Biol Chem 286:1420-1428. CrossRef Medline

Bhowmick R, Li M, Sun J, Baker SA, Insinna C, Besharse JC (2009) Photoreceptor IFT complexes containing chaperones, guanylyl cyclase 1 and rhodopsin. Traffic 10:648-663. CrossRef Medline

Chaitin MH, Burnside B (1989) Actin filament polarity at the site of rod outer segment disk morphogenesis. Invest Ophthalmol Vis Sci 30:24612469. Medline

Chang K, Marran K, Valentine A, Hannon GJ (2013) Creating an miR30based shRNA Vector. Cold Spring Harb Protoc 2013:631-635. CrossRef Medline

Chuang JZ, Zhao Y, Sung CH (2007) SARA-regulated vesicular targeting underlies formation of the light-sensing organelle in mammalian rods. Cell 130:535-547. CrossRef Medline

Concepcion F, Chen J (2010) Q344ter mutation causes mislocalization of rhodopsin molecules that are catalytically active: a mouse model of Q344ter-induced retinal degeneration. PLoS One 5:e10904. CrossRef Medline

Concepcion F, Mendez A, Chen J (2002) The carboxy-terminal domain is essential for rhodopsin transport in rod photoreceptors. Vision Res 42: 417-426. CrossRef Medline

Deretic D, Papermaster DS (1991) Polarized sorting of rhodopsin on post- 
Golgi membranes in frog retinal photoreceptor cells. J Cell Biol 113:12811293. CrossRef Medline

Deretic D, Papermaster DS (1993) Rab6 is associated with a compartment that transports rhodopsin from the trans-Golgi to the site of rod outer segment disk formation in frog retinal photoreceptors. J Cell Sci 106:803813. Medline

Deretic D, Huber LA, Ransom N, Mancini M, Simons K, Papermaster DS (1995) rab8 in retinal photoreceptors may participate in rhodopsin transport and in rod outer segment disk morphogenesis. J Cell Sci 108: 215-224. Medline

De Rienzo G, Gutzman JH, Sive H (2012) Efficient shRNA-mediated inhibition of gene expression in zebrafish. Zebrafish 9:97-107. CrossRef Medline

Duman JG, Tyagarajan K, Kolsi MS, Moore HP, Forte JG (1999) Expression of rab11a N124I in gastric parietal cells inhibits stimulatory recruitment of the H+-K+-ATPase. Am J Physiol 277:C361-C372. Medline

Fariss RN, Li ZY, Milam AH (2000) Abnormalities in rod photoreceptors, amacrine cells, and horizontal cells in human retinas with retinitis pigmentosa. Am J Ophthalmol 129:215-223. CrossRef Medline

Fotiadis D, Liang Y, Filipek S, Saperstein DA, Engel A, Palczewski K (2004) The $G$ protein-coupled receptor rhodopsin in the native membrane. FEBS Lett 564:281-288. CrossRef Medline

Gidon A, Bardin S, Cinquin B, Boulanger J, Waharte F, Heliot L, de la Salle H, Hanau D, Kervrann C, Goud B, Salamero J (2012) A Rab11A/ myosin $\mathrm{Vb} / \mathrm{Rab} 11-\mathrm{FIP} 2$ complex frames two late recycling steps of langerin from the ERC to the plasma membrane. Traffic 13:815-833. CrossRef Medline

Gilliam JC, Chang JT, Sandoval IM, Zhang Y, Li T, Pittler SJ, Chiu W, Wensel TG (2012) Three-dimensional architecture of the rod sensory cilium and its disruption in retinal neurodegeneration. Cell 151:1029-1041. CrossRef Medline

Green ES, Menz MD, LaVail MM, Flannery JG (2000) Characterization of rhodopsin mis-sorting and constitutive activation in a transgenic rat model of retinitis pigmentosa. Invest Ophthalmol Vis Sci 41:1546-1553. Medline

Gross AK, Decker G, Chan F, Sandoval IM, Wilson JH, Wensel TG (2006) Defective development of photoreceptor membranes in a mouse model of recessive retinal degeneration. Vision Res 46:4510-4518. CrossRef Medline

Grossman GH, Watson RF, Pauer GJ, Bollinger K, Hagstrom SA (2011) Immunocytochemical evidence of Tulp1-dependent outer segment protein transport pathways in photoreceptor cells. Exp Eye Res 93:658-668. CrossRef Medline

Hehnly H, Chen CT, Powers CM, Liu HL, Doxsey S (2012) The centrosome regulates the Rab11-dependent recycling endosome pathway at appendages of the mother centriole. Curr Biol 22:1944-1950. CrossRef Medline

Hollingsworth TJ, Gross AK (2012) Defective trafficking of rhodopsin and its role in retinal degenerations. Int Rev Cell Mol Biol 293:1-44. CrossRef Medline

Keady BT, Le YZ, Pazour GJ (2011) IFT20 is required for opsin trafficking and photoreceptor outer segment development. Mol Biol Cell 22:921930. CrossRef Medline

Knepp AM, Periole X, Marrink SJ, Sakmar TP, Huber T (2012) Rhodopsin forms a dimer with cytoplasmic helix 8 contacts in native membranes. Biochemistry 51:1819-1821. CrossRef Medline

Knödler A, Feng S, Zhang J, Zhang X, Das A, Peränen J, Guo W (2010) Coordination of Rab8 and Rab11 in primary ciliogenesis. Proc Natl Acad Sci U S A 107:6346-6351. CrossRef Medline

Lem J, Krasnoperova NV, Calvert PD, Kosaras B, Cameron DA, Nicolò M, Makino CL, Sidman RL (1999) Morphological, physiological, and biochemical changes in rhodopsin knockout mice. Proc Natl Acad Sci U S A 96:736-741. CrossRef Medline

Li BX, Satoh AK, Ready DF (2007) Myosin V, Rab11, and dRip11 direct apical secretion and cellular morphogenesis in developing Drosophila photoreceptors. J Cell Biol 177:659-669. CrossRef Medline

Li T, Snyder WK, Olsson JE, Dryja TP (1996) Transgenic mice carrying the dominant rhodopsin mutation P347S: evidence for defective vectorial transport of rhodopsin to the outer segments. Proc Natl Acad Sci U S A 93:14176-14181. CrossRef Medline

Litman BJ (1982) Purification of rhodopsin by concanavalin A affinity chromatography. Methods Enzymol 81:150-153. CrossRef Medline
Liu Q, Tan G, Levenkova N, Li T, Pugh EN Jr, Rux JJ, Speicher DW, Pierce EA (2007) The proteome of the mouse photoreceptor sensory cilium complex. Mol Cell Proteomics 6:1299-1317. CrossRef Medline

Lodowski KH, Lee R, Ropelewski P, Nemet I, Tian G, Imanishi Y (2013) Signals governing the trafficking and mistrafficking of a ciliary GPCR, rhodopsin. J Neurosci 33:13621-13638. CrossRef Medline

Mazelova J, Astuto-Gribble L, Inoue H, Tam BM, Schonteich E, Prekeris R, Moritz OL, Randazzo PA, Deretic D (2009) Ciliary targeting motif VxPx directs assembly of a trafficking module through Arf4. EMBO J 28:183192. CrossRef Medline

Moritz OL, Tam BM, Hurd LL, Peränen J, Deretic D, Papermaster DS (2001) Mutant rab8 impairs docking and fusion of rhodopsin-bearing postGolgi membranes and causes cell death of transgenic Xenopus rods. Mol Biol Cell 12:2341-2351. CrossRef Medline

Muresan V, Joshi HC, Besharse JC (1993) Gamma-tubulin in differentiated cell types: localization in the vicinity of basal bodies in retinal photoreceptors and ciliated epithelia. J Cell Sci 104:1229-1237. Medline

Panfoli I, Musante L, Bachi A, Ravera S, Calzia D, Cattaneo A, Bruschi M, Bianchini P, Diaspro A, Morelli A, Pepe IM, Tacchetti C, Candiano G (2008) Proteomic analysis of the retinal rod outer segment disks. J Proteome Res 7:2654-2669. CrossRef Medline

Papermaster DS, Dreyer WJ (1974) Rhodopsin content in the outer segment membranes of bovine and frog retinal rods. Biochemistry 13:24382444. CrossRef Medline

Pasqualato S, Senic-Matuglia F, Renault L, Goud B, Salamero J, Cherfils J (2004) The structural GDP/GTP cycle of Rab11 reveals a novel interface involved in the dynamics of recycling endosomes. J Biol Chem 279: 11480-11488. CrossRef Medline

Peet JA, Bragin A, Calvert PD, Nikonov SS, Mani S, Zhao X, Besharse JC, Pierce EA, Knox BE, Pugh EN Jr (2004) Quantification of the cytoplasmic spaces of living cells with EGFP reveals arrestin-EGFP to be in disequilibrium in dark adapted rod photoreceptors. J Cell Sci 117:3049-3059. CrossRef Medline

Price BA, Sandoval IM, Chan F, Nichols R, Roman-Sanchez R, Wensel TG, Wilson JH (2012) Rhodopsin gene expression determines rod outer segment size and rod cell resistance to a dominant-negative neurodegeneration mutant. PLoS One 7:e49889. CrossRef Medline

Ren M, Xu G, Zeng J, De Lemos-Chiarandini C, Adesnik M, Sabatini DD (1998) Hydrolysis of GTP on rab11 is required for the direct delivery of transferrin from the pericentriolar recycling compartment to the cell surface but not from sorting endosomes. Proc Natl Acad Sci U S A 95:61876192. CrossRef Medline

Sandoval IM, Price BA, Chan F, Sammons JD, Gross AK, Wilson JH, Wensel TG (2014) Abrupt onset of mutations in a developmentally regulated gene during terminal differentialtion of post-mitotic photoreceptor neurons in mice. PLoS One 9:e108135. CrossRef Medline

Satoh AK, O’Tousa JE, Ozaki K, Ready DF (2005) Rab11 mediates postGolgi trafficking of rhodopsin to the photosensitive apical membrane of Drosophila photoreceptors. Development 132:1487-1497. CrossRef Medline

Schlüter MA, Pfarr CS, Pieczynski J, Whiteman EL, Hurd TW, Fan S, Liu CJ, Margolis B (2009) Trafficking of Crumbs3 during cytokinesis is crucial for lumen formation. Mol Biol Cell 20:4652-4663. CrossRef Medline

Shetty KM, Kurada P, O’Tousa JE (1998) Rab6 regulation of rhodopsin transport in Drosophila. J Biol Chem 273:20425-20430. CrossRef Medline

Silva JM, Li MZ, Chang K, Ge W, Golding MC, Rickles RJ, Siolas D, Hu G, Paddison PJ, Schlabach MR, Sheth N, Bradshaw J, Burchard J, Kulkarni A, Cavet G, Sachidanandam R, McCombie WR, Cleary MA, Elledge SJ, Hannon GJ (2005) Second-generation shRNA libraries covering the mouse and human genomes. Nat Genet 37:1281-1288. CrossRef Medline

Sparrow DB, Latinkic B, Mohun TJ (2000) A simplified method of generating transgenic Xenopus. Nucleic Acids Res 28:E12. CrossRef Medline

Standfuss J, Xie G, Edwards PC, Burghammer M, Oprian DD, Schertler GF (2007) Crystal structure of a thermally stable rhodopsin mutant. J Mol Biol 372:1179-1188. CrossRef Medline

Sung CH, Chuang JZ (2010) The cell biology of vision. J Cell Biol 190:953963. CrossRef Medline

Sung CH, Makino C, Baylor D, Nathans J (1994) A rhodopsin gene mutation responsible for autosomal dominant retinitis pigmentosa results in a 
protein that is defective in localization to the photoreceptor outer segment. J Neurosci 14:5818-5833. Medline

Tam BM, Moritz OL, Hurd LB, Papermaster DS (2000) Identification of an outer segment targeting signal in the $\mathrm{COOH}$ terminus of rhodopsin using transgenic Xenopus laevis. J Cell Biol 151:1369-1380. CrossRef Medline

Tam BM, Xie G, Oprian DD, Moritz OL (2006) Mislocalized rhodopsin does not require activation to cause retinal degeneration and neurite outgrowth in Xenopus laevis. J Neurosci 26:203-209. CrossRef Medline

Ullrich O, Reinsch S, Urbé S, Zerial M, Parton RG (1996) Rab11 regulates recycling through the pericentriolar recycling endosome. J Cell Biol 135: 913-924. CrossRef Medline

Wang J, Morita Y, Mazelova J, Deretic D (2012) The Arf GAP ASAP1 provides a platform to regulate Arf4- and Rab11-Rab8-mediated ciliary receptor targeting. EMBO J 31:4057-4071. CrossRef Medline

Wensel TG, Gross AK, Chan F, Sykoudis K, Wilson JH (2005) Rhodopsin-
EGFP knock-ins for imaging quantal gene alterations. Vision Res 45: 3445-3453. CrossRef Medline

Wikström K, Reid HM, Hill M, English KA, O’Keeffe MB, Kimbembe CC, Kinsella BT (2008) Recycling of the human prostacyclin receptor is regulated through a direct interaction with Rab1la GTPase. Cell Signal 20: 2332-2346. CrossRef Medline

Xiong B, Bayat V, Jaiswal M, Zhang K, Sandoval H, Charng WL, Li T, David G, Duraine L, Lin YQ, Neely GG, Yamamoto S, Bellen HJ (2012) Crag is a GEF for Rab11 required for rhodopsin trafficking and maintenance of adult photoreceptor cells. PLoS Biol 10:e1001438. CrossRef Medline

Yeh TY, Peretti D, Chuang JZ, Rodriguez-Boulan E, Sung CH (2006) Regulatory dissociation of Tctex-1 light chain from dynein complex is essential for the apical delivery of rhodopsin. Traffic 11:1495-1502.

Young RW (1967) The renewal of photoreceptor cell outer segments. J Cell Biol 33:61-72. CrossRef Medline 